$$
\text { CONF- } 961102--5
$$

\title{
STABILITY OF NEGATIVE CENTRAL MAGNETIC SHEAR DISCHARGES IN THE DIII-D TOKAMAK
}

\author{
by \\ E.J. STRAIT, T.A. CASPER, M.S. CHU, J.R. FERRON, A. GAROFAL, \\ C.M. GREENFIELD, R.J. LaHAYE, L.L. LAO, E.A. LAZARUS, R.L. MILLER, \\ G.A. NAVRATIL, C. REN, B.W. RICE, I. SEMENOV, A.C. SIPS, \\ F.X. SÖLDNER, B.W. STALLARD, T.S. TAYLOR, AND A.D. TURNBULL
}

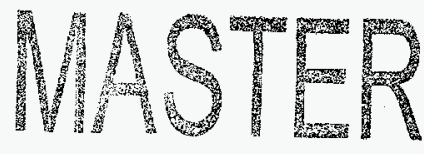




\section{STABILITY OF NEGATIVE CENTRAL MAGNETIC SHEAR DISCHARGES IN THE DIII-D TOKAMAK}

This is a preprint of an invited paper to be presented at the Thirty-Eighth American Physical Society Annual Meeting, Division of Plasma Physics, November 11-15, 1996, Denver, Colorado and to be published in Phys. Plasmas.

E.J. STRAIT, T.A. CASPER, ${ }^{*}$ M.S. CHU, J.R. FERRON, A. GAROFAL, ${ }^{\Delta}$ C.M. GREENFIELD, R.J. La HAYE, L.L. LAO, E.A. LAZARUS, ${ }^{\diamond}$ R.L. MILLER, G.A. NAVRATIL, ${ }^{\triangle}$ C. REN, ${ }^{\ddagger}$ B.W. RICE, ${ }^{\star}$ I. SEMENOV, ${ }^{\dagger}$ A.C. SIPS, $\$$ F.X. SÖLDNER, ${ }^{\S}$ B.W. STALLARD, ${ }^{*}$ T.S. TAYLOR, AND A.D. TURNBULL

"Lawrence Livermore National Laboratory, Livermore, California.

${ }^{\Delta}$ Columbia University, New York, New York.

Oak Ridge National Laboratory, Oak Ridge, Tennessee.

¥University of Wisconsin, Madison, Wisconsin.

†TRINITI Laboratory, Troitsk, Russia.

§JET Joint Undertaking, Abingdon, United Kingdom.

Work supported by the U.S. Department of Energy under Contract No. DE-ACO3-89ER51114

GA PROJECT 3466

DECEMBER 1996 


\section{DISCLAMER}

Portions of this document may be illegible in electronic image products. Images are produced from the best available original document. 


\title{
Stability of negative central magnetic shear discharges in the DIII-D tokamak
}

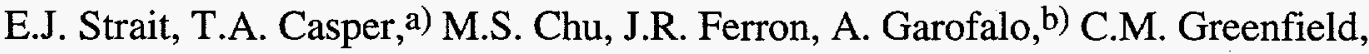 \\ R.J. La Haye, L.L. Lao, E.A. Lazarus, ${ }^{\text {c) }}$ R.L. Miller, G.A. Navratil, b) C. Ren, d) \\ B.W. Rice, ${ }^{\text {a) }}$ I. Semenov, ${ }^{\text {e) }}$ A.C.C. Sips, ${ }^{f)}$ F.X. Söldner, ${ }^{f)}$ B.W. Stallard, a) \\ T.S. Taylor, and A.D. Turnbull
}

General Atomics, P.O. Box 85608, San Diego, California 92186-9784

Discharges with negative central magnetic shear (NCS) hold the promise of enhanced fusion performance in advanced tokamaks. However, stability to long wavelength magnetohydrodynamic modes is needed to take advantage of the improved confinement found in NCS discharges. The stability limits seen in DIII-D [J.L. Luxon and L.G. Davis, Fusion Technology 8, 441 (1985)] experiments depend on the pressure and current density profiles and are in good agreement with stability calculations. Discharges with a strongly peaked pressure profile reach a disruptive limit at low beta, $\beta_{\mathrm{N}}=\beta(\mathrm{I} / \mathrm{aB})^{-1} \leq 2.5(\% \mathrm{~m} \mathrm{~T} / \mathrm{MA})$, caused by an $n=1$ ideal internal kink mode or a global resistive instability close to the ideal stability limit. Discharges with a broad pressure profile reach a soft beta limit at significantly higher beta, $\beta_{N}=4$ to 5 , usually caused by instabilities with $n>1$ and usually driven near the edge of the plasma. With broad pressure profiles, the experimental stability limit is independent of the magnitude of negative shear but improves with the internal inductance, corresponding to lower current density near the edge of the plasma. Understanding of the stability limits in NCS discharges has led to record DIII-D fusion performance in discharges with a broad pressure profile and low edge current density.

PACS No. 52.55.Fa, 52.35.Py, 52.30.Jb, 52.25.Fi

\footnotetext{
a)Lawrence Livermore National Laboratory, Livermore, California.

b) Columbia University, New York, New York.

c) Oak Ridge National Laboratory, Oak Ridge, Tennessee.

d)University of Wisconsin, Madison, Wisconsin.

e)TRINITI Laboratory, Troitsk, Russia.

f)JET Joint Undertaking, Abingdon, United Kingdom.
} 


\section{INTRODUCTION}

Plasmas with a central region of negative magnetic shear represent a promising path to improved tokamak fusion performance. Calculations show that such a configuration can provide stability at high beta, good energy confinement, and a large fraction of bootstrap current. ${ }^{1-3}$ (Magnetic shear is defined as $\mathrm{s}=(2 \mathrm{~V} / q)(\mathrm{d} q / \mathrm{dV}) \approx(\mathrm{r} / q)(\mathrm{d} q / \mathrm{dr})$, where $q$ is the tokamak safety factor, $\mathrm{V}$ is the volume enclosed in a magnetic flux surface, and $\mathrm{r}$ is the minor radius.) Negative magnetic shear stabilizes short-wavelength ballooning modes, ${ }^{4}$ leading to improved stability at high beta. $\left(\beta=2 \mu_{0}\langle\mathrm{p}\rangle / \mathrm{B}^{2}\right.$ is the ratio of volumeaveraged plasma pressure to magnetic field pressure.) Negative magnetic shear is also predicted to stabilize toroidal drift modes which are believed to contribute to anomalous transport in tokamaks. 5,6,2 The bootstrap current generated by the pressure gradient is similar to the current density profile needed for negative central magnetic shear (NCS), allowing a self-consistent plasma configuration with high confinement and modest requirements for external current drive. Some of the advantages of this configuration have already been realized. Recent experiments with negative central magnetic shear plasmas have demonstrated reduced local transport and improved global energy confinement in high-power discharges in DIII-D ${ }^{7}$ and the Tokamak Fusion Test Reactor $(\text { TFTR })^{8}$ and, more recently, in several other large tokamaks, 9,10 leading to very high values of central ion temperature, central pressure, and fusion power gain.

A significant reduction of energy and particle transport in the core region is perhaps the most remarkable characteristic of NCS plasmas. 11 Early experiments showed evidence of reduced transport in a core region with negative central shear. ${ }^{12-15}$ More recent experiments have demonstrated a reduction to neoclassical levels of ion thermal diffusivity, particle diffusivity, ${ }^{8,16}$ and electron thermal diffusivity. ${ }^{17-19}$ In DIII-D discharges with an L-mode (low confinement) edge, the enhanced core confinement leads to energy confinement times more than double the typical $L$-mode values, ${ }^{20}$ while discharges with an $\mathrm{H}$-mode (high confinement) edge reach neoclassical levels of ion thermal transport throughout the discharge volume ${ }^{21}$ accompanied by further improvement of the global energy confinement time. The reduction in transport is accompanied by suppression of small-scale turbulence, ${ }^{21-23}$ in which $\mathrm{E} \times \mathrm{B}$ flow shear is believed to play an important role. $24-26,11$

Stability at high beta is needed in order to accommodate the large pressures and pressure gradients associated with improved confinement. Although negative magnetic shear 
stabilizes high-n ballooning modes, stability to low $n$ modes remains a challenge. The stability of NCS plasmas is predicted to depend strongly on discharge shaping and the form of the pressure and current density profiles. Ideal magnetohydrodynamic (MHD) stability calculations predict that for highly triangular DIII-D discharges, the $n=1$ stability limit in normalized beta, $\beta_{\mathrm{N}}=\beta(\mathrm{aB} / \mathrm{I})(\% \mathrm{~m} \mathrm{~T} / \mathrm{MA})$, rises from less than 2 to greater than 5 as the radial pressure profile is varied from a peaked to broad form. 27 Resistive stability calculations give similar results, ${ }^{28}$ with the resistive limit lying slightly below the ideal limit. At the ideal stability limit, with a broad pressure profile the fusionweighted beta, $\beta^{*}=2 \mu_{0}\left\langle\mathrm{p}^{2}\right\rangle^{1 / 2} / \mathrm{B}^{2}$, reaches values greater than $9 \%$. The gain in $\beta$ with a broad pressure profile more than compensates for the reduction in the ratio $\beta^{*} / \beta=$ $\left\langle\mathrm{p}^{2}\right\rangle^{1 / 2} /\langle\mathrm{p}\rangle$, leading to larger $\beta^{*}$ and larger predicted fusion power with a broad pressure profile. The ideal MHD stability at high normalized beta relies on a nearby conducting wall; 3 plasma rotation allows similar stabilization in the presence of a finite conductivity wall, ${ }^{29}$ as shown in DIII-D experiments. ${ }^{30,31}$ Strong discharge shaping is beneficial for fusion performance in two ways. With a broad pressure profile, the predicted $\beta_{\mathrm{N}}$ limit for a strongly shaped cross section is more than double the limit for a circular cross section. In addition, the larger plasma current capacity of the shaped cross section yields a larger $\beta$ for the same value of $\beta_{\mathrm{N}}$. This combination of enhanced confinement and stability at high beta, with strong discharge shaping, has led to record fusion performance in DIII-D deuterium plasmas. This performance extrapolates to a fusion gain $\mathrm{Q}_{\mathrm{DT}}=0.32$ in an equivalent deuterium-tritium plasma. 21,11

In this paper, we discuss the MHD stability of strongly shaped negative central shear (NCS) plasmas in DIII-D. The production of NCS plasmas and control of the pressure and safety factor profiles is discussed in Section II. The performance of these discharges is limited, in most cases, by low-n MHD instabilities in good agreement with stability calculations. The impact of pressure profile peaking is shown in Section III. As predicted, discharges with strongly peaked pressure profiles encounter a stability limit at low normalized beta, while discharges with broad pressure profiles reach much higher beta. Section IV discusses the range of instabilities which ultimately limit the performance of discharges with broad pressure profiles. The role of the current density profile is discussed in Section V. As with monotonic $q$-profiles, the stability to low $-\mathrm{n}$ modes is improved by reducing the current density in the outer region of the plasma. The application of all of these elements to increasing the fusion performance in DIII-D is discussed in Section VI. Finally, the conclusions are presented in Section VII. 


\section{NEGATIVE CENTRAL SHEAR PLASMAS IN DIII-D}

Plasmas with a wide range of $q$ profiles are reliably produced and diagnosed in DIII-D. The negative central shear configuration is created by the use of low-power neutral beam injection beginning early in the initial plasma current ramp in order to raise the electron temperature and slow the inward penetration of the inductively driven current. ${ }^{32}$ At the end of the current ramp, the neutral beam power is increased, heating the plasma to high beta. The form of the "target" $q$-profile at the start of high-power heating can be varied through the plasma density during the current ramp, as well as the power and timing of the early beam injection. Measurements of the profile of the local field pitch angle with a 16-channel Motional Stark Effect (MSE) diagnostic ${ }^{33}$ allow accurate reconstruction of the $q$-profile throughout the discharge, using information on the plasma shape from external magnetic diagnostics. The radial electric field associated with plasma rotation and large pressure gradients is properly accounted for in the interpretation of the MSE measurements. ${ }^{34}$ The radial electric field is determined from charge exchange recombination spectroscopy (CER) measurements. 35

High performance DIII-D discharges with enhanced core confinement do not always have negative magnetic shear. The $\mathrm{E} \times \mathrm{B}$ flow shear, which in DIII-D is associated with strong toroidal rotation of the plasma, is believed to be a major factor responsible for the enhanced core confinement. 24,11 Nevertheless, most of these discharges begin with a negative shear "target" $q$-profile, which appears to be an important factor in entering the regime of enhanced core confinement. Furthermore, these discharges typically have low central magnetic shear, which still removes the high $-\mathrm{n}$ ballooning mode limit over a large volume of the plasma. Therefore, in this paper, we will continue to refer to this class of discharges as "NCS" discharges based on their common features of low central magnetic shear and enhanced core confinement.

For purposes of stability and transport analysis, measured pressure profile data are incorporated into detailed reconstructions with the EFIT equilibrium code, 36 as shown in Fig. 1. In addition to MSE data and external magnetic measurements, input includes the electron density from Thomson scattering and four $\mathrm{CO}_{2}$ laser interferometer chords, the electron temperature from Thomson scattering and electron cyclotron emission measurements, and the ion temperature and $\mathrm{Z}$ effective from charge exchange 
recombination spectroscopy. The fast ion pressure profile is calculated assuming classical slowing down of the beam ions.
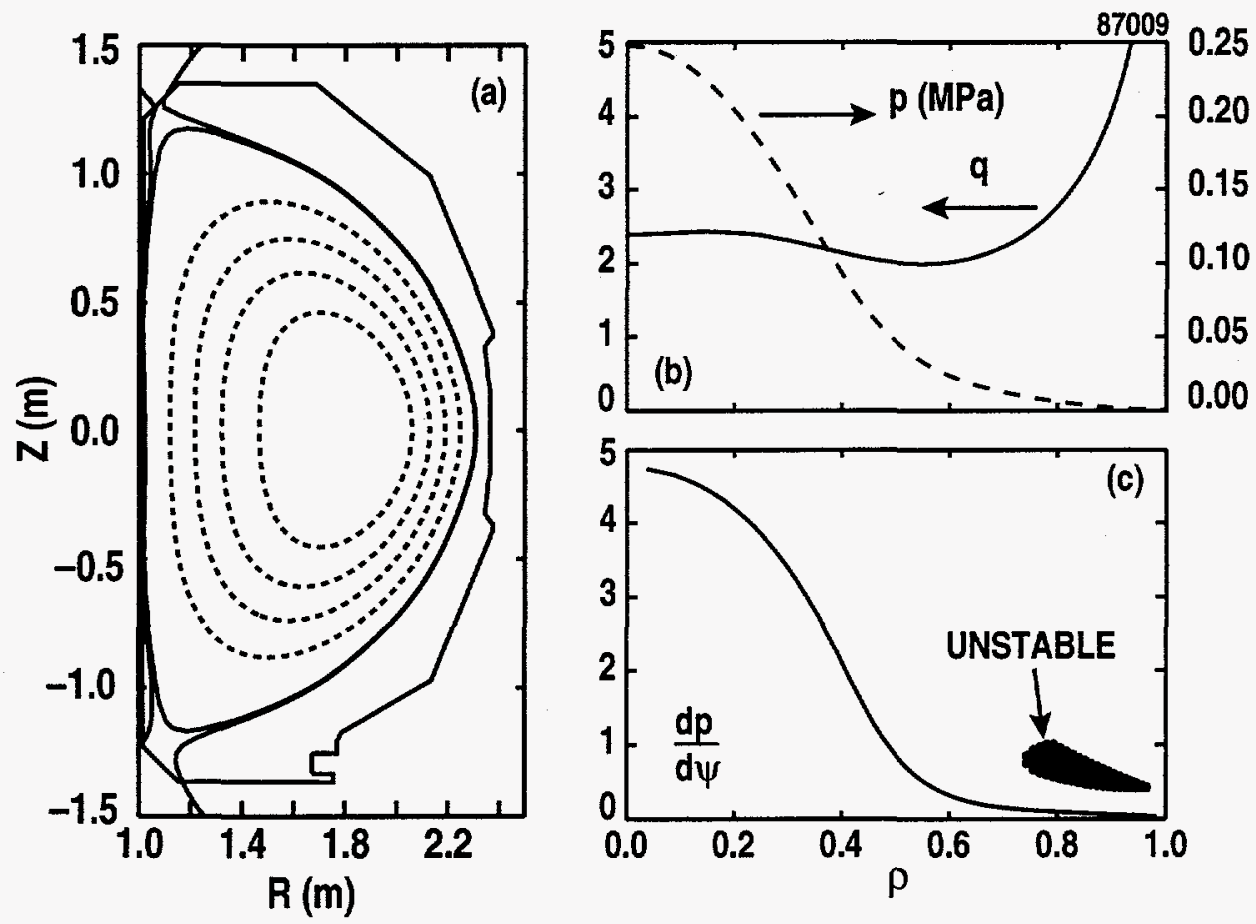

Fig. 1. A typical NCS discharge with an L-mode edge, showing (a) discharge shape, (b) pressure and safety factor profiles, and (c) the pressure gradient profile and calculated ballooning mode limit. Discharge 87009, $\mathrm{I}_{\mathrm{p}}=1.6 \mathrm{MA}, \mathrm{B}_{\mathrm{T}}=2.1 \mathrm{~T}, \mathrm{P}_{\mathrm{NB}}=12 \mathrm{MW}, \beta_{\mathrm{N}}=2.0$.

The principal means of varying the pressure profile in DIII-D is the choice between operation with a low confinement (L-mode) or high confinement (H-mode) edge. Strong central peaking of the pressure profile is observed in NCS discharges with an L-mode edge, as seen in Fig. 1(b). An "internal transport barrier" is associated with large gradients of ion temperature and density at a normalized radius $\mathrm{r} / \mathrm{a} \leq 0.5$, leading to central ion temperatures of $20 \mathrm{keV}$ or larger and pressure peaking factors, $\left.\mathrm{p}_{0} / \mathrm{p}\right\rangle$, greater than 5. High-n ballooning stability analysis with the CAMINO code ${ }^{37}$ shows that this discharge has access to the second stable regime everywhere except for a narrow region near the edge, as seen in Fig. 1(c). The removal of the high-n ballooning mode limit in the plasma core is characteristic of discharges with low or negative magnetic shear, ${ }^{4}$ and may be associated with the reduced core transport. 38,39 A further advantage of negative central shear is seen in Fig. 1(a): the low poloidal field near the magnetic axis which is associated with negative magnetic shear increases the elongation of the internal flux surfaces, leading to a larger volume in the central, high-pressure region. NCS discharges 
with an H-mode edge have similar features, except that the pressure profile is broader with pressure peaking factors on the order of 2 to 3 . The maximum central pressure remains comparable to that of the $\mathrm{L}$-mode case, allowing $\mathrm{H}$-mode edge discharges to reach significantly higher beta.

The performance of NCS plasmas is generally limited by MHD instabilities with low to moderate toroidal mode number, $\mathrm{n} \leq 5$. Power balance alone, based on the instantaneous energy confinement time $\tau_{\mathrm{E}}=\mathrm{W} /(\mathrm{P}-\mathrm{dW} / \mathrm{dt})$ at peak performance and the $20 \mathrm{MW}$ of available heating power, predicts steady-state $(\mathrm{dW} / \mathrm{dt}=0)$ values of beta far greater than are ever reached in these experiments. The type of limiting instability observed depends on the details of the plasma profiles, as will be discussed below. The most important difference is that discharges with an L-mode edge and strongly peaked pressure profiles almost invariably end in a fast disruption, while discharges with an $\mathrm{H}-$ mode edge and broader pressure profiles experience a softer limit with a more gradual degradation of confinement. 


\section{EFFECTS OF PRESSURE PROFILE PEAKING}

Discharges with strongly peaked pressure profiles are limited by disruptions to a relatively low value of beta, $\beta_{N} \leq 2.5$. As seen in Fig. 2, the plasma energy and neutron rate rise steadily until the disruption. The disruption is preceded by a growing instability with toroidal mode number $\mathrm{n}=1$, as shown in Fig. 2(b), which has several remarkable features. The mode grows rapidly, with a growth time $\gamma^{-1}=0.1$ to $0.5 \mathrm{~ms}$, and grows to very large amplitude, $\delta \mathrm{B}_{\theta} / \mathrm{B}_{\theta} \cong 0.1$ at the outboard vacuum vessel wall, while still rotating. This growth rate is one to two orders of magnitude faster than the typical growth of resistive instabilities near the beta limit, but an order of magnitude slower than is usually observed for ideal kink modes at the beta limit. Comparison of the mode frequency with the plasma rotation frequency measured by charge exchange recombination spectroscopy indicates that the disruption precursor is located just inside the radius of minimum $q$, near the inner $q=2$ surface.

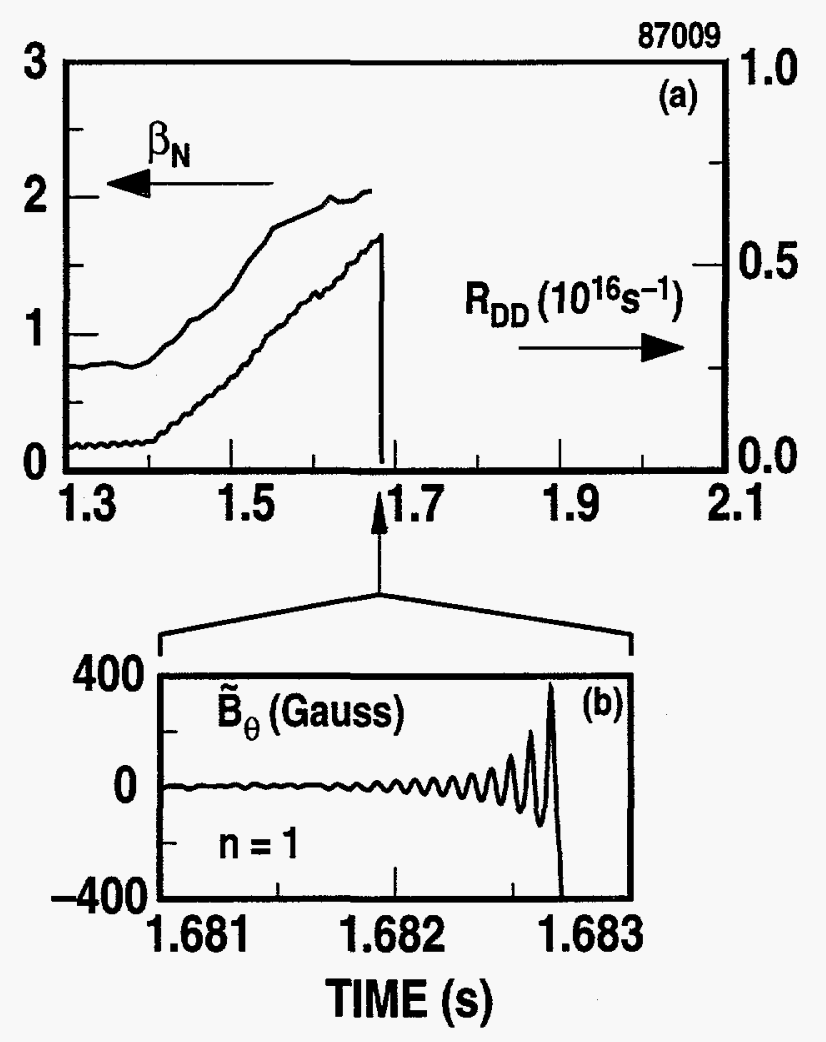

Fig. 2. Time evolution of an NCS discharge with Lmode edge and peaked pressure profile, showing (a) beta and D-D fusion neutron rate, and (b) a time expansion of the disruption's magnetic precursor. Discharge 87009, as in Fig. 1. 
The observed disruption limit is consistent with ideal and resistive MHD stability calculations. The stability limit for the ideal $n=1$ kink mode calculated with the $\mathrm{GATO}^{40}$ code is typically found to lie at beta values up to $25 \%$ higher than the experimentally measured beta. However, for those discharges significantly below the ideal limit, the $n=1$ resistive stability limit calculated with the MARS code 29,41 agrees well with the experimentally measured value. Resistive stability calculations find two modes with similar stability thresholds, a localized resistive interchange mode and a more global mode. The resistive interchange mode is destabilized when the product $\mathrm{p}^{\prime} q^{\prime}$ is positive, as in the central negative shear region. The global mode evidently corresponds to the disruption, while the more localized mode may correspond to bursts of instability which are often seen in the negative shear region before the disruption and at lower $\beta$ values. The disruption threshold in beta is approximately constant for $1.3<q_{\min }<3$, consistent with resistive stability calculations and suggesting that the beta limit is not directly related to the low shear region near $q_{\mathrm{min}}$. Calculations with MARS show increased mixing of the resistive interchange mode with the global mode as beta increases, 28,27 providing a possible direct role in the disruption for the resistive interchange mode. Alternatively, the reduction of magnetic shear and rotational shear which occur during the earlier bursts of the resistive interchange mode may contribute to destabilization of the global mode and lead to a disruption.

Discharges with broader pressure profiles reach much higher values of beta, again consistent with stability calculations. As shown in Fig. 3, both ideal and resistive $n=1$ stability calculations predict that the maximum normalized beta rises strongly as the pressure profile becomes broader. $27,28,24$ In DIII-D, the primary means for broadening the pressure profile is a controlled transition from $\mathrm{L}$-mode to $\mathrm{H}$-mode. ${ }^{21,11}$ Typically, the $\mathrm{L}-\mathrm{H}$ transition is made as late as possible in order to postpone the buildup of edge density which can reduce the central heating power density. Figure 3 shows the trajectories of two typical discharges. The discharge which remains in L-mode encounters a stability limit at low beta and disrupts. In the second discharge, the pressure peaking factor $\mathrm{p}_{0} /\langle\mathrm{p}\rangle$ decreases rapidly after the $\mathrm{L}-\mathrm{H}$ transition. Near the stability limit, the core pressure gradient in the $\mathrm{H}$-mode case is significantly smaller than that of the $\mathrm{L}-$ mode case, although $\beta_{\mathrm{N}}$ is much higher. This discharge does not disrupt and reaches a beta about twice that of the L-mode case. 


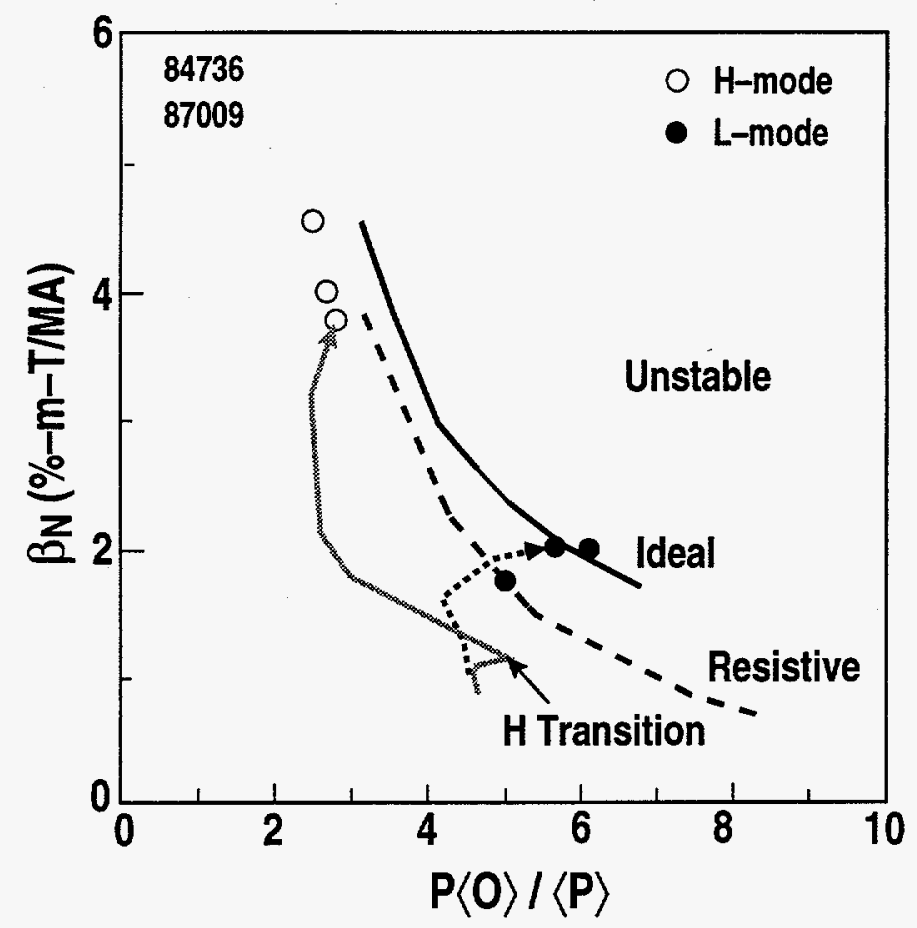

Fig. 3. Experimental behavior compared to calculated stability limits. Calculated ideal and resistive $n=1$ stability limits are plotted against the pressure peaking factor. Time histories of a typical $\mathrm{L}$-mode and $\mathrm{H}$-mode discharge are shown (arrows), with the maximum beta for a few other representative discharges (circles). 


\section{STABILITY WITH BROAD PRESSURE PROFILE}

Although NCS plasmas with an $\mathrm{H}$-mode edge and broad pressure profiles do not disrupt, both experimental evidence and stability calculations show that they are near several stability limits. These discharges exhibit several different types of instabilities at high beta, rather than the single type of beta-limiting instability observed in the cases with an L-mode edge and peaked pressure profiles. This more complex behavior is a characteristic, perhaps even a definition, of profiles which are more nearly optimized so as to approach several stability limits at once.

In some discharges with broad pressure profiles, an internal instability with moderate mode number limits the central pressure gradient. In the example shown in Fig. 4, a burst of MHD activity with toroidal mode number $n=3$ occurs during the high power phase of the discharge. The initial growth of the mode is rapid, with a growth time $\gamma^{-1} \approx 0.2 \mathrm{~ms}$.

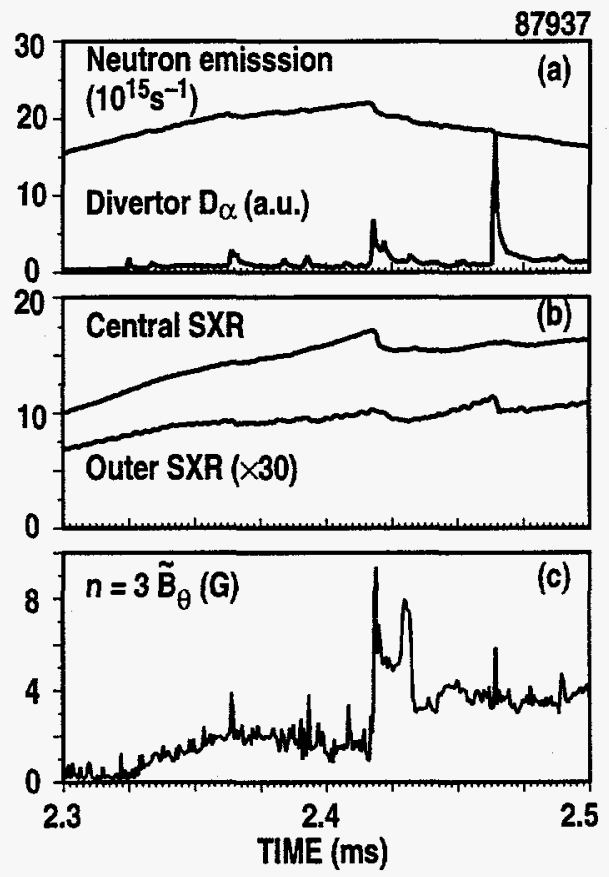

Fig. 4. Time evolution of a high performance discharge with broad pressure profile, limited by an internal instability. (a) D-D neutron emission and divertor $D_{\alpha}$ emission, (b) central $(\rho=0)$ and outer ( $\rho=0.6$ ) soft $X$-ray chords, (c) $n=3$ mode amplitude from Fourier analysis of a magnetic probe signal. Discharge $87937, \mathrm{I}_{\mathrm{p}}=2.1 \mathrm{MA}$, $\mathrm{B}_{\mathrm{T}}=2.1 \mathrm{~T}, \mathrm{P}_{\mathrm{NB}}=20 \mathrm{MW}, \beta_{\mathrm{N}}=3.8$. 
The D-D fusion neutron rate, a sensitive indicator of the quality of confinement in the core of the plasma, shows a small prompt decrease at the time of the instability, followed by a slower decay. The central soft $\mathrm{X}$-ray emission also drops at the time of the instability, showing a reduction of central temperature, with little change in the emission from the outer region of the plasma. These observations confirm the central location of the instability. Despite the burst of $D_{\alpha}$ at the time of the instability, the behavior is quite different from the edge-localized mode (ELM) which occurs later at about $t=2.465 \mathrm{~s}$. Soft X-ray and neutron emission show that the energy loss in the ELM occurs in the outer region of the plasma, while the center is not affected.

Ideal MHD stability calculations show this plasma to be at the threshold of instability for an internal $n=3 \mathrm{kink}$ mode driven by the central pressure gradient. With an equilibrium reconstruction just before the time of the instability, GATO calculations show the plasma to be stable to low $-\mathrm{n}$ ideal kink modes. However, if beta is raised slightly, by only $5 \%$, the $n=3$ kink mode becomes unstable. The $n=1$ and $n=2$ modes become unstable only at larger beta. The centrally localized structure of the calculated mode (shown in Fig. 5) agrees well with the observed energy loss, and the predominant $\mathrm{m}=4$ component is consistent with the experimental identification of the instability as an $\mathrm{m} / \mathrm{n}=4 / 3$ mode. This instability may be an "infernal mode" 42 which can be destabilized

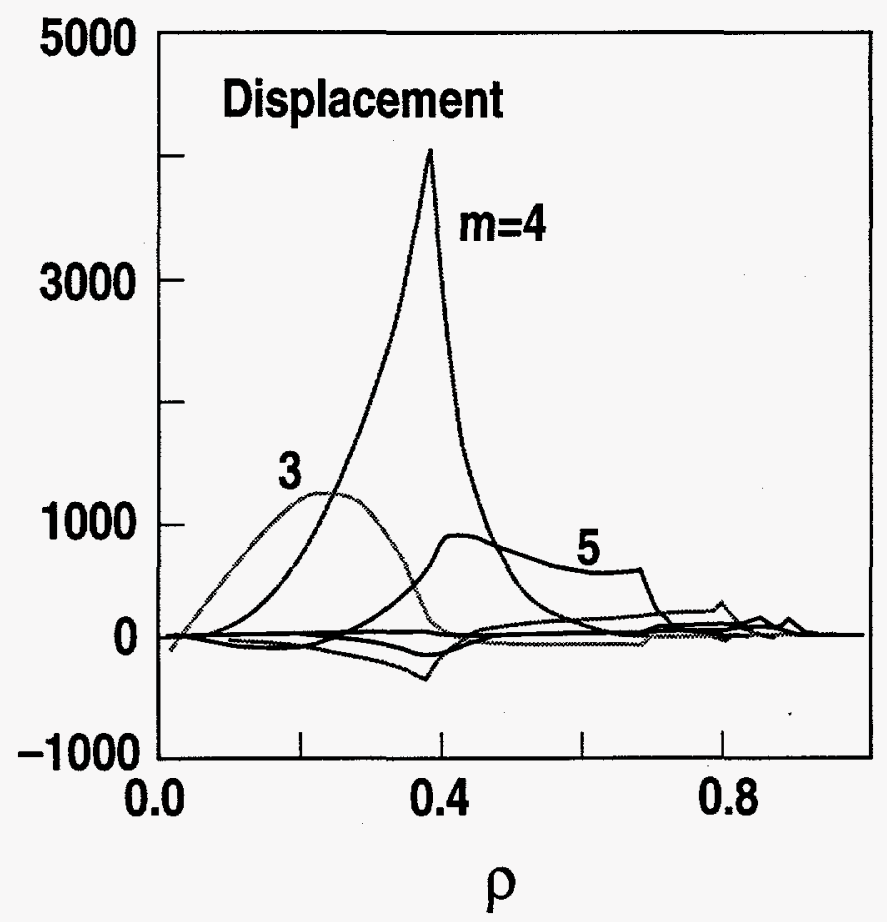

Fig. 5. Calculated $n=3$ ideal MHD mode structure for the discharge of Fig. 4. 
by low shear and large pressure gradient and which is predicted to set the beta limit in some NCS cases with low $q_{\min } .43$ However, these centrally localized instabilities are not the most frequently observed in NCS discharges with broad pressure profiles.

More typically, discharges with a broad pressure profile first encounter a stability limit near the edge. In the example shown in Fig. 6 , an instability at $t=1.875$ ms causes a reduction of about $10 \%$ in stored energy. The central electron temperature remains unchanged while the temperature in the outer region drops, as seen in Figs. 6(c) and 6(d), indicating that the instability is localized in the outer part of the plasma. The magnetic perturbation associated with this instability consists of a single pulse with no precursor oscillation, as seen in Fig. 6(e).

This instability is strongly localized in both time and space, as shown in Fig. 7. As the single pulse rotates past the poloidal array of magnetic probes, it is seen only once by most of them and, at most, twice by some implying a growth and decay time on the order of the rotation period, $\gamma^{-1} \cong 0.15 \mathrm{~ms}$. The width of the pulse relative to the rotation period corresponds to a toroidal mode number $n=5$, but of course the non-sinusoidal character implies a distribution of several toroidal modes rotating together with $n=5$ as the largest. Unlike more central MHD modes, this one is observed to rotate in the electron diamagnetic direction. This is consistent with a location near the edge of the plasma, where the $\mathrm{E} \times \mathrm{B}$ drift is dominated by the diamagnetic drift associated with the large $\mathrm{H}$-mode edge pressure gradient, rather than by the neutral beam-driven toroidal rotation.

This instability in the outer part of the plasma is very likely the same as in the termination of the ELM-free phase in VH-mode discharges. 44 The characteristics of the plasma edge are essentially the same in the two cases, and the VH-mode termination events have a magnetic signature very similar to the one shown here. Ideal MHD stability calculations for the VH-mode termination have shown unstable edge-localized kink modes whose growth rate increases with toroidal mode number, in the range $n=1$ to 3. These instabilities require both a large pressure gradient and a large current density near the edge. 44,45 In the case of VH-mode discharges, the edge current density increases with time as a result of the bootstrap current driven by the edge pressure gradient. In the case of NCS discharges, the inductive current ramp also contributes to raising the edge current density. For example, in the discharge shown in Figs. 6 and 7 , 

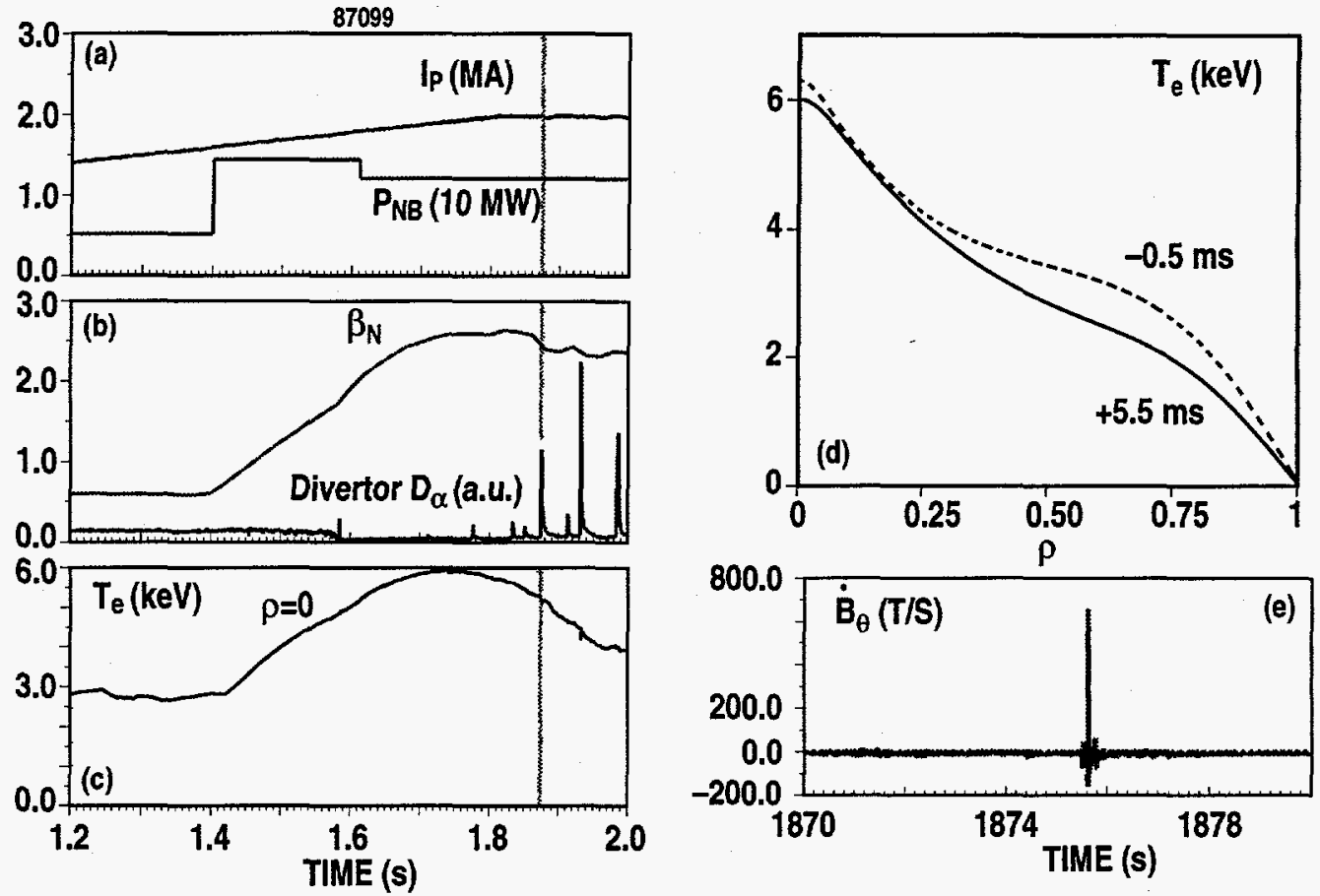

Fig. 6. Time evolution of a high performance discharge with broad pressure profile, limited by an edge driven instability. (a) plasma current and neutral beam power, (b) normalized beta and divertor $D_{\alpha}$ emission, (c) central electron temperature, (d) radial profiles of electron temperature before and after the instability, and (e) time expansion of the magnetic precursor. Discharge $87099, \mathrm{I}_{\mathrm{p}}=1.9 \mathrm{MA}$, $\mathrm{B}_{\mathrm{T}}=2.1 \mathrm{~T}, \mathrm{P}_{\mathrm{NB}}=12 \mathrm{MW}, \beta_{\mathrm{N}}=2.5$.

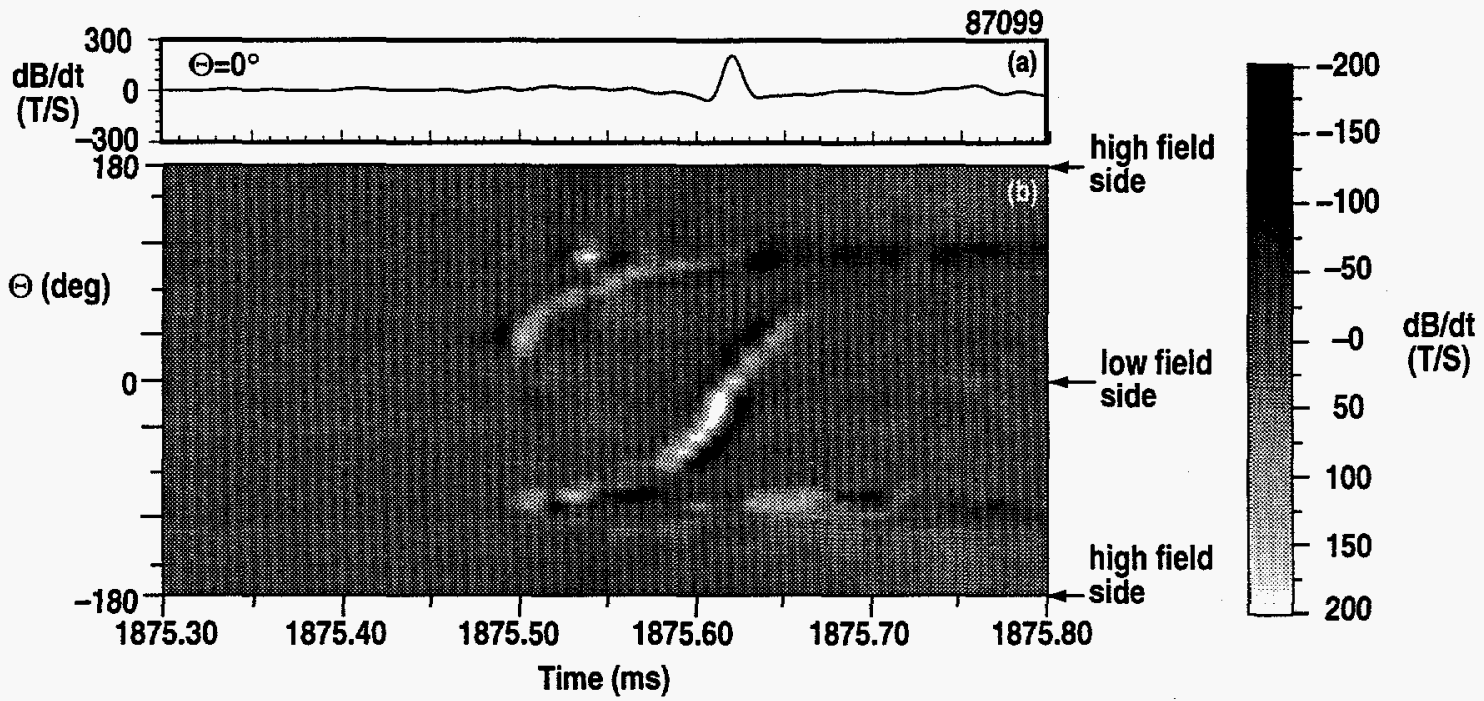

Fig. 7. Time and poloidal angle dependence of the instability from Fig. 6. (a) time evolution of $\mathrm{dB}_{\theta} / \mathrm{dt}$ from a magnetic probe at the outboard (low field side) midplane, and (b) contour plot of $\mathrm{dB}_{\theta} / \mathrm{dt}$ versus time and poloidal angle. 
full heating power was applied before the end of the current ramp leading to a very broad current density profile (internal inductance $\ell_{i}=0.75$ ).

Large current density or current density gradients near the edge can also destabilize low- $n$ modes. A smaller number of NCS discharges with an $\mathrm{H}-$ mode edge and strongly negative central shear terminate with the growth of a non-rotating $n=1$ mode in the outer region of the plasma. The mode grows much more slowly than the others discussed previously, with a growth time $\gamma^{-1} \gtrsim 10 \mathrm{~ms}$ suggesting a resistive mode. Resistive stability calculations for one such case using the MARS code predict a marginally stable $\mathrm{n}=1$ mode with large contributions from both $\mathrm{m}=2$ and $\mathrm{m}=3$, in good agreement with the experimental mode identification. The calculated mode is stable with an ideally conducting wall, but becomes unstable if the wall is expanded to 1.05 times the nominal DIII-D wall radius; this is consistent with the experimental observation that the mode only grows in a non-rotating state, where the resistive vacuum vessel wall no longer provides stabilization. This discharge was unstable at $\beta_{N}=3.4$, while a companion discharge with weaker central shear reversal was stable at $\beta_{\mathrm{N}}=3.8$ in both experiment and calculation. 


\section{EFFECTS OF THE $q$-PROFILE}

The magnitude of negative shear in the plasma core has surprisingly little influence on the stability of discharges with broad, $\mathrm{H}$-mode edge pressure profiles. The central portion of the $q$-profile in NCS discharges can be characterized by $q_{\min }$, the minimum $q$ value, and $\Delta q=q_{0}-q_{\min }$, a measure of negative shear. Discharges with mild heating during the current ramp and smaller $\Delta q$ are consistently observed to reach higher beta than those with stronger early heating and large $\Delta q$. However, this turns out to be an artifact of a broad correlation between increasing $\Delta q$ and increasing $q_{\min }$, resulting from the technique used for producing negative shear in these discharges. For a fixed value of $q_{\text {min }}$, there is little or no dependence of the beta limit on $\Delta q$. Consistent with these experimental results, $\mathrm{n}=1$ ideal stability calculations show little or no dependence of the stability limit on $\Delta q$. The high-n ballooning mode limit, of course, has no dependence on $\Delta q$ for a fixed $q_{\min }$, as long as $\Delta q$ is greater than zero.

The current density profile in the outer part of the plasma appears to be much more important in determining low-n stability limits with broad pressure profiles. For a fixed value of $\Delta q$ there is a clear decrease in beta with increasing $q_{\min }$, in contrast to the beta limit for peaked pressure profiles (Section III). This trend is also seen in the entire data base of $\mathrm{H}$-mode edge NCS discharges, as shown in Fig. 8(a). As $q_{\min }$ increases, the total
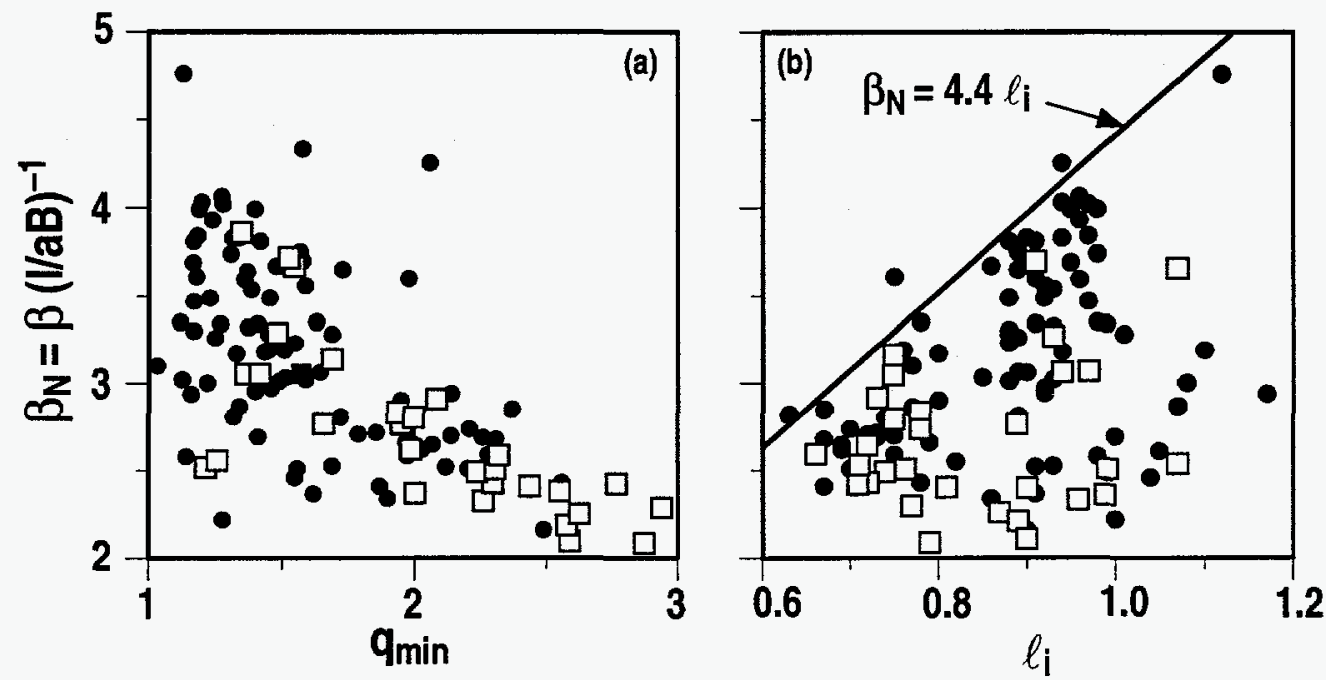

Fig. 8. Dependence of the beta limit on the current density profile as parameterized by (a) the minimum $q$ value, and (b) the internal inductance, for double-null NCS discharges with $\mathrm{H}$-mode edge and weak or positive shear (circles) or strong negative shear (squares). 
current outside the radius of $q_{\min }$ must increase. This may be unfavorable for stability, as suggested by the edge-localized kink stability calculations described in Section IV. The amount of current density near the edge can also be parameterized roughly by $\ell_{i}$, the internal inductance. When the data set of Fig. 8(a) is plotted against $\ell_{\mathrm{i}}$, there appears a trend of increasing beta with increasing internal inductance, as seen in Fig. 8(b). Because $q_{\min }$ and $\ell_{\mathbf{i}}$ are correlated, the same discharges appear in the top of the distribution for both plots. As indicated in Fig. 8(b), these results agree well with the empirical scaling $\beta_{N} \leq 4 \ell_{i}$ which was found previously for monotonic $q$-profiles. ${ }^{46,47}$ The $\ell_{i}$ scaling for broad pressure profiles has also been qualitatively supported by ideal kink stability calculations. ${ }^{48}$ This agreement with the stability limit for monotonic $q$-profiles is not surprising since, in most cases, the beta limit for NCS discharges is caused by instabilities in the outer, positive-shear region of the plasma. 


\section{FUSION PERFORMANCE}

Record values of fusion power for DIII-D have been reached by utilizing the understanding of stability in NCS discharges, culminating in a discharge with a measured $\mathrm{D}-\mathrm{D}$ fusion gain $\mathrm{QDD}=\mathrm{P}_{\text {fusion }} / \mathrm{P}_{\text {beam }}$ of $1.5 \times 10^{-3}$, which extrapolates to an equivalent value QDT $=0.32$ for a deuterium-tritium fuel mixture. 21,11 Since fusion power density is approximately proportional to the square of the plasma pressure, the fusion power gain varies roughly as $Q=P_{\text {fusion }} / P_{\text {in }} \sim \beta \tau_{E} B^{2} \sim \beta_{N} H I^{2} B$, where $\tau_{E}$ is the energy confinement time and $\mathrm{H}$ is the ratio of $\tau_{\mathrm{E}}$ to the prediction of ITER-89P L-mode scaling. 49 Fusion power can therefore be increased by operating near the stability limit at high normalized beta, and indeed, the maximum $Q_{D D}$ was reached at $\beta_{N}=4$. As discussed above in Section III, stability to low-n modes at high normalized beta is attained through the use of broad pressure profiles with an $\mathrm{H}$-mode edge. The broad pressure profile for the discharge with highest QDD in DIII-D, shown in Fig. 9, is in contrast to the peaked pressure profile for an L-mode edge case shown earlier in Fig. 1. Low-n stability at high normalized beta also requires a low current density near the edge, corresponding to high $\ell_{\mathrm{i}}$ or low $q_{\mathrm{min}}$, as was shown in Section V. The $q$-profile for the high QDD case in Fig. 9 has a significantly lower $q_{\min }$ than the case of Fig. 1 . Although the central shear of the high QDD case is quite small, as is typical for high performance discharges with low $q_{\mathrm{min}}$, it is sufficient to maintain a large region of access to the second stable regime for
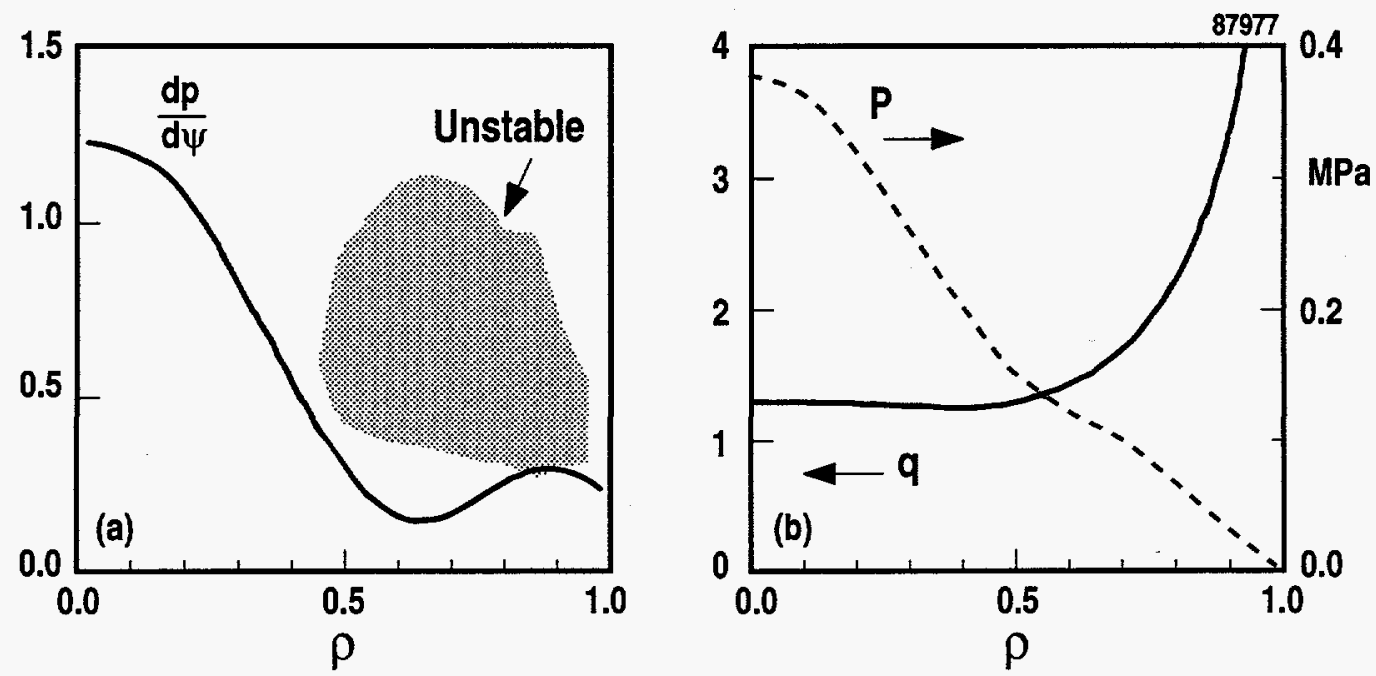

Fig. 9. Highest QDD discharge, showing (a) the pressure gradient profile and calculated ballooning mode limit, and (b) pressure and safety factor profiles. Discharge $87977, I_{p}=$ $2.2 \mathrm{MA}, \mathrm{B}_{\mathrm{T}}=2.1 \mathrm{~T}, \mathrm{P}_{\mathrm{NB}}=18 \mathrm{MW}, \beta_{\mathrm{N}}=4.0, \mathrm{H} \geq 4$. 
ballooning modes, as also shown in Fig. 9. In this discharge the bootstrap current provides only about half of the total plasma current; steady-state operation would require additional non-inductive current drive in the region of moderate pressure gradient near the half-radius. However, transport and stability calculations indicate that further optimization of the $q$-profile should allow stable discharges with comparable beta and a larger fraction of bootstrap current, well aligned with the total plasma current. ${ }^{3}$

Strong discharge shaping and large plasma current were also important stabilityrelated elements in the achievement of high fusion performance 21,50 Because the fusion gain is proportional to $\mathrm{I}^{2}$, substantial improvements in performance can be realized by increasing the plasma current, as shown in Fig. 10. With other parameters fixed, this

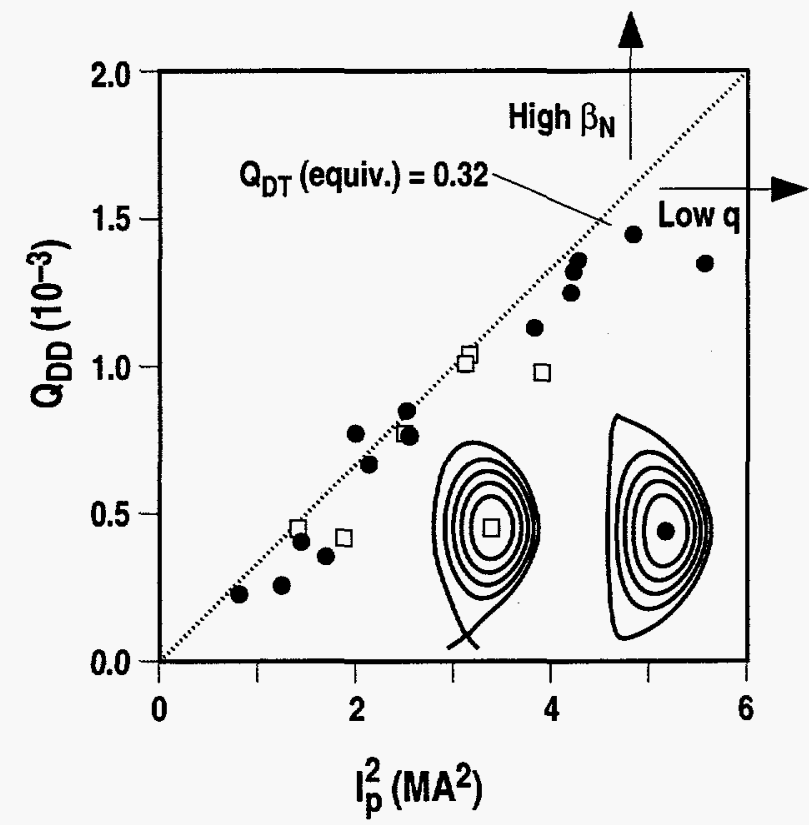

Fig. 10. Fusion gain $Q_{D D}=P_{\text {fusion }} / P_{\text {in }}$ versus plasma current squared. High triangularity double-null discharges (circles) and low triangularity single-null discharges (squares) have similar dependence on $\mathrm{I}^{2}$ but the high triangularity cases can reach higher current.

means reducing the safety factor; the high QDD discharge in DIII-D was achieved at a moderately low value of $q_{95}=4.2$. Strong discharge shaping improves fusion performance at fixed $\beta_{\mathrm{N}}$ by allowing higher plasma current without reducing $q$. Furthermore, strong shaping is predicted to raise the $\beta_{\mathrm{N}}$ limit. ${ }^{27}$ The high QDD discharge in DIII-D was a strongly shaped double-null configuration with an elongation $\kappa=2.2$ and triangularity $\delta=0.85$. Recent experiments in JET-like single-null discharges with lower 
elongation and triangularity had similar $\mathrm{H}$ and $\beta_{\mathrm{N}}$ and, consequently, a similar scaling of QDD with plasma current, ${ }^{51,52}$ also shown in Fig. 10 . As expected, however, the singlenull discharges were restricted to a smaller current and, hence, a QDD of only $1.0 \times 10^{-3}$. It should be noted that the highest-current point of each data set in Fig. 10 represents the best of only a handful of discharges, without extensive optimization. They show that a current limit has not been reached, and that the potential exists for further increases in fusion performance. 


\section{CONCLUSIONS}

The fusion performance of NCS discharges in DIII-D is limited by low- $\mathrm{n}$ MHD stability. The stability limits depend on the pressure and current density profiles, in good agreement with stability calculations. Discharges with an L-mode edge and strongly peaked pressure profile reach a disruptive limit at low beta, $\beta_{\mathrm{N}} \leq 2.5$, caused by an $n=1$ ideal internal kink mode or a global resistive instability close to the ideal stability limit. Discharges with an $\mathrm{H}$-mode edge and broad pressure profile reach a soft beta limit at significantly higher beta, usually caused by instabilities with $n>1$ and usually driven near the edge of the plasma. With peaked pressure profiles, the experimental stability limit is independent of $q_{\mathrm{min}}$, consistent with resistive stability predictions, but the resistive interchange mode is expected to become more unstable as $\Delta q$ increases. On the other hand, with broad pressure profiles, the experimental stability limit is independent of $\Delta q$ but increases with decreasing $q_{\mathrm{min}}$, corresponding to lower current density near the edge of the plasma and higher $\ell_{i}$. The highest fusion performance in DIII-D has been achieved in discharges with a broad pressure profile and low edge current density.

Further improvements in stability and fusion performance should still be possible. High fusion performance in single-null NCS discharges 51,52 has been maintained with 995 as low as 3, suggesting that double-null performance can be improved by increasing the plasma current and reducing the safety factor from the previous value of $q 95 \approx 4$. Stability calculations predict that with wall stabilization, normalized beta as high as 5 should be possible, and at somewhat higher safety factor, $q_{95} \approx 5$, values up to $\beta_{\mathrm{N}}=4.8$ have already been achieved. 24 Extending this high $\beta_{\mathrm{N}}$ to the larger plasma current and lower $q$ of the high fusion performance experiments would significantly improve the fusion power. Clearly, attention must be paid to the form and evolution of the pressure and current density profiles. Electron cyclotron current drive and divertor pumping for high triangularity plasmas are new profile control capabilities for DIII-D which should help to improve stability and increase the duration of the high performance in future experiments. 


\section{ACKNOWLEDGMENTS}

This is a report of work supported by the U.S. Department of Energy under Contract No. DE-AC03-89ER51114. 


\section{REFERENCES}

1T. S. Taylor, H. St.John, A. D. Turnbull, Y. R. Lin-Liu, K. H. Burrell, V. S. Chan, M. S. Chu, J. R. Ferron, L. L. Lao, R. J. La Haye, E. A. Lazarus, R. L. Miller, P. A. Politzer, D. P. Schissel, E. J. Strait, Plasma Physics and Contr. Fusion 36, B229 (1994).

2C. Kessel, J. Manickam, G. Rewoldt, W. M. Tang, Phys. Rev. Lett. 72, 1212 (1994).

${ }^{3}$ A. D. Turnbull, T. S. Taylor, Y. R. Lin-Liu, H. St.John, Phys. Rev. Lett. 74, 718 (1995).

4J. M. Greene and M. S. Chance, Nucl. Fusion 21, 453 (1981).

5B. B. Kadomtsev and O. P. Pogutse, Sov. Physics JETP 24, 1172 (1967).

6R. E Waltz, G. D. Kerbel, J. Milovich, and G. W. Hammett, Phys. Plasmas 2, 2408 (1995).

${ }^{7}$ E. J. Strait, L. L. Lao, M. E. Mauel, B. W. Rice, T. S. Taylor, K. H. Burrell, M. S. Chu, E. A. Lazarus, T. H. Osborne, S. J. Thompson, and A. D. Turnbull, Phys. Rev. Lett. 75, 4421 (1995).

${ }^{8}$ F. M. Levinton, M. C. Zarnstorff, S. H. Batha, M. Bell, R. E. Bell, R. V. Budny, C. Bush, Z. Chang, E. Frederickson, A. Janos, J. Manickam, A. Ramsey, S. A. Sabbagh, G. L. Schmidt, E. J. Synakowski, G. Taylor, Phys. Rev. Lett. 75 , 4417 (1995).

${ }^{9}$ C. Gormezano and the JET Team, "Optimization of JET Plasmas with Current Profile Control," Plasma Phys. and Controlled Nucl. Fusion Research 1996 (International Atomic Energy Agency, Vienna, 1997), to be published.

${ }^{10} \mathrm{~K}$. Ushigusa and the JT-60 Team, "Steady State Operation Research in JT-60U," Plasma Phys. and Controlled Nucl. Fusion Research 1996 (International Atomic Energy Agency, Vienna, 1997), to be published. 
${ }^{11}$ C. M. Greenfield, D. P. Schissel, B. W. Stallard, E. A. Lazarus, G. A. Navratil, K. H. Burrell, T. A. Casper, J. C. DeBoo, E. J. Doyle, R. J. Fonck, C. B. Forest, P. Gohil, R. J. Groebner, M. Jakubowski, L. L. Lao, M. Murakami, C. C. Petty, C. L. Rettig, T. L. Rhodes, B. W. Rice, H. E. St. John, G. M. Staebler, E. J. Strait, T. S. Taylor, A. D. Turnbull, K. L. Tritz, R. E. Waltz, and The DIII-D Team, "Transport and Performance in DIII-D Discharges with Weak or Negative Central Magnetic Shear," submitted to Phys. Plasmas (this conference).

${ }^{12}$ E. A. Lazarus, M. S. Chu, J. R. Ferron, F. J. Helton, J. T. Hogan, A. G. Kellman, L. L. Lao, J. B. Lister, T. H. Osborne, R. Snider, E. J. Strait, T. S. Taylor, A. D. Turnbull, Phys. Fluids B 3, 2220 (1991); E. A. Lazarus, L. L. Lao, T. H. Osborne, T. S. Taylor, A. D. Turnbull, M. S. Chu, A. G. Kellman, E. J. Strait, J. R. Ferron, R. J. Groebner, W. W. Heidbrink, T. N. Carlstrom, F. J. Helton, C. L. Hsieh, S. I. Lippmann, D. P. Schissel, R. T. Snider and D. Wròblewski, Phys. Fluids B 4, 3644 (1992).

${ }^{13}$ M. Hugon, B. Ph. van Milligen, P. Smeulders, L. C. Appel, D. V. Bartlett, D. Boucher, A. W. Edwards, L. G. Eriksson, C. W. Gowers, T. C. Hender, G. Huysmans, J. J. Jacquinot, P. Kupschus, L. Porte, P. H. Rebut, D. F. H. Start, F. Tibone, B. J. D. Tubbing, M. L. Watkins, W. Zwingman, Nucl. Fusion 32, 33 (1992).

${ }^{14}$ G. T. Hoang, C. Gil, E. Joffrin, D. Moreau, A. Becoulet, P. Bibet, J. P. Bizarro, R. V. Budny, J. Carrasco, J. P. Coulon, C. de Michelis, T. Dudok de Wit, P. Garbet-Monier, M. Goniche, R. Guirlet, T. Hutter, S. M. Kaye, J. LaSalle, L. Laurent, P. LeCoustey, X. Litaudon, M. Mattioli, Y. Peysson, A.-L. Pecquet, G. Rey, S. A. Sabbagh, B. Saoutic, G. Tonon, J. C. Vallet, Nucl. Fusion 34, 75 (1994).

${ }^{15}$ Y. Kamada, K. Ushigusa, O. Naito, Y. Neyatani, T. Ozeki, K. Tobita, S. Ishida, R. Yoshino, M. Kikuchi, M. Mori, H. Ninomiya, Nucl. Fusion 34, 1605 (1994).

16B. W. Rice, K. H. Burrell, L. L. Lao, G. Navratil, B. W. Stallard, E. J. Strait, T. S. Taylor, M. E. Austin, T. A. Casper, M. S. Chu, C. B. Forest, P. Gohil, R. J. Groebner, W. W. Heidbrink, A. W. Hyatt, H. Ikezi, R. J. La Haye, E. A. Lazarus, Y. R. Lin-Liu, M. E. Mauel, W. H. Meyer, C. L. Rettig, D. P. Schissel, H. E. St.John, P. L. Taylor, A. D. Turnbull and the DIII-D Team, Phys. Plasmas 3, 1983 (1996).

${ }^{17}$ C. B. Forest, C. C. Petty, M. E. Austin, F. W. Baity, K. H. Burrell, S. C. Chiu, M. S. Chu, J. S. DeGrassie, P. Gohil, A. W. Hyatt, H. Ikezi, E. A. Lazarus, M. Murakami, R. I. Pinsker, M. Porkolab, R. Prater, B. W. Rice, G. M. Staebler, E. J. Strait and T. S. Taylor, Phys. Rev. Lett. 77, 3141 (1996). 
${ }^{18 X}$. Litaudon, R. Arslanbekov, G. T. Hoang, E. Joffrin, F. Kazarian-Vibert, D. Moreau, Y. Peysson, P. Bibet, P. Froissard, M. Goniche, G. Rey, J. Ferron, and K. Kupfer, Plasma Phys. Control. Fusion 38, 1603 (1996)

${ }^{19}$ T. Fujita, S. Ide, H. Shirai, O. Naito, Y. Koide, S. Takeji, H. Kubo, S. Ishida and M. Kikuchi, "Internal Transport Barrier for Electrons in JT-60U Reversed Shear Discharges," submitted to Phys. Rev. Lett.; T. Fujita, S. Ide, H. Kimura, Y. Koide, T. Oikawa, S. Takeji, H. Shirai, T. Ozeki, Y. Kamada, S. Ishida and the JT-60 Team, "Enhanced Core Confinement in JT-60U Reversed Shear Discharges," Plasma Phys. and Controlled Nucl. Fusion Research 1996 (International Atomic Energy Agency, Vienna, 1997) to be published.

${ }^{20}$ B. W. Rice, E. A. Lazarus, M. E. Austin, K. H. Burrell, T. A. Casper, R. J. Groebner, P. Gohil, C. B. Forest, H. Ikezi, L. L. Lao, M. E. Mauel, G. A. Navratil, B. W. Stallard, E. J. Strait, and T. S. Taylor, Nucl. Fusion 36, 1271(1996).

${ }^{21}$ E. A. Lazarus, G. A. Navratil, C. M. Greenfield, E. J. Strait, M. E. Austin, K. H. Burrell, T. A. Casper, D. R. Baker, J. C. DeBoo, E. J. Doyle, R. Durst, J. R. Ferron, C. B. Forest, P. Gohil, R. J. Groebner, W. W. Heidbrink, R.-M. Hong, W. A. Houlberg, A. W. Howald, C.-L. Hsieh, A. W. Hyatt, G. L. Jackson, J. Kim, L. L. Lao, C. J. Lasnier, A. W. Leonard, J. Lohr, R. J. La Haye, R. Maingi, R. L. Miller, M. Murakami, T. H. Osborne, L. J. Perkins, C. C. Petty, C. L. Rettig, T. L. Rhodes, B. W. Rice, S. A. Sabbagh, D. P. Schissel, J. T. Scoville, R. T. Snider, G. M. Staebler, B. W. Stallard, R. D. Stambaugh, H. E. St.John, R. E. Stockdale, P. L. Taylor, D. M. Thomas, A. D. Turnbull, M. R. Wade, R. Wood, and D. Whyte, Phys. Rev. Lett. 77, 2714 (1996).

${ }^{22}$ E. Mazzucato, S. H. Batha, M. Beer, M. Bell, R. E. Bell, R. V. Budny, C. Bush, T. S. Hahm, G. W. Hammett, F. M. Levinton, R. Nazikian, H. Park, G. Rewoldt, G. L. Schmidt, E. J. Synakowski, W. M. Tang, G. Taylor, and M. C. Zarnstorff, Phys. Rev. Lett. 77, 3145 (1996).

${ }^{23}$ E. J. Doyle, K. H. Burrell, T. N. Carlstron, S. Coda, J. C. DeBoo, R. D. Durst, R. J. Fonck, P. Gohil, C. M. Greenfield, R. J. Groebner, J. Kim, K. W. Kim, R. J. La Haye, L. L. Lao, E. A. Lazarus, R. A. Moyer, G. Navratil, T. H. Osborne, W. A. Peebles, C. L. Rettig, T. L. Rhodes, B. W. Rice, D. P. Schissel, G. M. Staebler, T. S. Taylor, D. M. Thomas, E. J. Strait and R. E. Waltz, "Physics of Turbulence Control and Transport Barrier Formation in DII-D," Plasma Phys. and Controlled Nucl. Fusion Research 1996 (International Atomic Energy Agency, Vienna, 1997) to be published. 
${ }^{24}$ L. L. Lao, K. H. Burrell, T. S. Casper, V. S. Chan, M. S. Chu, J. C. DeBoo, E. J. Doyle, R. D. Durst, C. B. Forest, C. M. Greenfield, R. J. Groebner, F. L. Hinton, Y. Kawano, E. A. Lazarus, Y. R. Lin-Liu, M. E. Mauel, W. H. Meyer, R. L. Miller, G. A. Navratil, T. H. Osborne, Q. Peng, C. L. Rettig, G. Rewoldt, T. L. Rhodes, B. W. Rice, D. P. Schissel, B. W. Stallard, E. J. Strait, W. M. Tang, T. S. Taylor, A. D. Turnbull, R. E. Waltz, and the DIII-D Team, Phys. Plasmas 3, 1951 (1996).

${ }^{25}$ D. P. Schissel, C. M. Greenfield, J. C. DeBoo, L. L. Lao, E. A. Lazarus, G. A. Navratil, B. W. Rice, G. M. Staebler, B. W. Stallard, E. J. Strait, H. E. St.John, M. E. Austin, K. H. Burrell, T. A. Casper, D. R. Baker, V. S. Chan, E. J. Doyle, J. R. Ferron, C. B. Forest, P. Gohil, R. J. Groebner, W. W. Heidbrink, R.-M. Hong, A. W. Howald, C.-L. Hsieh, A. W. Hyatt, G. L. Jackson, J. Kim, C. J. Lasnier, A. W. Leonard, J. Lohr, R. J. La Haye, R. Maingi, R. L. Miller, M. Murakami, T. H. Osborne, C. C. Petty, C. L. Rettig, T. L. Rhodes, S. Sabbagh, J. T. Scoville, R. T. Snider, R. D. Stambaugh, R. E. Stockdale, P. L. Taylor, T. S. Taylor, D. M. Thomas, M. R. Wade, R. E. Waltz, R. D. Wood, and D. G. Whyte, "Local Analysis of Confinement and Transport in Neutral Beam-Heated DIII-D Discharges with Negative Magnetic Shear," Plasma Phys. and Controlled Nucl. Fusion Research 1996 (International Atomic Energy Agency, Vienna, 1997) to be published.

${ }^{26}$ K. H. Burrell, "Effects of ExB Velocity Shear and Magnetic Shear on Turbulence and Transport in Magnetic Confinement Devices," submitted to Phys. Plasmas (this conference).

${ }^{27}$ A. D. Turnbull, M. S. Chu, T. S. Taylor, T. A. Casper, J. M. Greene, C. M. Greenfield, R. J. La Haye, L. L. Lao, B. J. Lee, R. L. Miller, C. Ren, C. L. Rettig, T. L. Rhodes, B. W. Rice, O. Sauter, E. J. Strait, K. Tritz, submitted to Plasma Physics and Controlled . Nuclear Fusion Research, 1996 (International Atomic Energy Agency, Vienna, 1997) to be published.

${ }^{28}$ M. S. Chu, J. M. Greene, L. L. Lao, R. J. Miller, A. Bondeson, O. Sauter, B. W. Rice, E. J. Strait, T. S. Taylor, A. D. Turnbull, Phys. Rev. Lett. 77, 2710 (1996).

${ }^{29}$ A. Bondeson and D. J. Ward, Phys. Rev. Lett. 72, 2709 (1994).

30E. J. Strait, T. S. Taylor, A. D. Turnbull, J. R. Ferron, L. L. Lao, B. Rice, O. Sauter, S. J. Thompson, and D. Wròblewski, Phys. Rev. Lett. 74, 2483 (1995). 
${ }^{31}$ T. S. Taylor, E. J. Strait, L. L. Lao, M. Mauel, A. D. Turnbull, K. H. Burrell, M. S. Chu, J. R. Ferron, R. J. Groebner, R. J. La Haye, B. W. Rice, R. T. Snider, S. J. Thompson, D. Wròblewski and D. J. Lightly, Phys. Plasmas 2, 2390 (1995).

32B. W. Rice, T. S. Taylor, K. H. Burrell, T. A. Casper, C. B. Forest, H. Ikezi, L. L. Lao, E. A. Lazarus, M. E. Mauel, B. W. Stallard, E. J. Strait, Plasma Phys. and Control. Fusion 38, 869 (1996).

${ }^{33}$ B. W. Rice, D. G. Nilson, D. Wroblewski, Rev. Sci. Instrum. 66, 373 (1995).

${ }^{34}$ B. W. Rice, K. H. Burrell, and L. L. Lao, "Effect of Plasma Radial Electric Field on Motional Stark Effect Measurements and Equilibrium Reconstruction," General Atomics Report GA-A22480 (1996), submitted to Nucl. Fusion.

35P. Gohil, K. H. Burrell, R. J. Groebner, J. Kim, W. C. Martin, E. L. McKee, and R. P. Seraydarian, in Proc. 14th IEEE/NPS Symposium on Fusion Engineering (Institute of Electrical and Electronics Engineers, Piscataway, New Jersey), Vol. II, 1199 (1992).

${ }^{36}$ L. L. Lao, J. R. Ferron, R. J. Groebner, W. Howl, H. St. John, E. J. Strait, T. S. Taylor, Nucl. Fusion 30, 1035 (1990).

${ }^{37}$ M. S. Chance, Theory of Fusion Plasmas (Varenna), Editrice Compositori, Bologna (1987) 87.

38P. A. Politzer, T. Casper, C. B. Forest, P. Gohil, W. W. Heidbrink, A. W. Hyatt, R. A. James, R. Jong, L. L. Lao, M. Makowski, W. Meyer, G. D. Porter, G. T. Sager, B. W. Stallard, H. St.John, S. J. Thompson, A. D. Turnbull, D. Wroblewski, Phys. Plasmas 1, 1545 (1994).

${ }^{39}$ B. W. Stallard, T. A. Casper, M. E. Fenstermacher, C. B. Forest, P. Gohil, W. W. Heidbrink, A. W. Hyatt, R. A. James, R. A. Jong, L. L. Lao, M. A. Makowski, W. H. Meyer, P. A. Politzer, G. D. Porter, G. T. Sager, H. St.John, S. J. Thompson, A. D. Turnbull, D. Wroblewski, Proc. 15th Int. Conf., Seville, Spain, 1994, in Plasma Physics and Controlled Nuclear Fusion Research, (IAEA, Vienna, 1995), Vol. II, p. 251.

40L. C. Bernard, F. J. Helton, R. W. Moore, Comput. Phys. Commun. 24, 377 (1981). 
${ }^{41}$ M. S. Chu, J. M. Greene, T. H. Jensen, R. L. Miller, A. Bondeson, R. W. Johnson, M. E. Mauel, Phys. Plasmas 2, 2236 (1995).

42J. Manickam, N. Pomphrey, A. M. M. Todd, Nucl. Fusion 27, 1461 (1987).

${ }^{43}$ M. W. Phillips, M. C. Zarnstorff, J. Manickam, F. M. Levinton, M. H. Hughes, Phys. Plasmas 3, 1673 (1996).

${ }^{44}$ E. J. Strait, T. S. Taylor, A. D. Turnbull, M. S. Chu, J. R. Ferron, L. L. Lao, T. H. Osborne, Proc. 20th EPS Conf., Lisbon, 1993, in Controlled Fusion and Plasma Physics Vol. 17C, Part I, 211 (1993).

45 J. R. Ferron, L. L. Lao, T. H. Osborne, O. Sauter, E. J. Strait, T. S. Taylor, S. J. Thompson, A. D. Turnbull, Proc. 21st EPS Conf., Montpellier, 1994, in Controlled Fusion and Plasma Physics Vol. 18B, Part I, (1994) p. 86.

${ }^{46}$ T. S. Taylor, E. A. Lazarus, M. S. Chu, J. R. Ferron, F. J. Helton, W. Howl, G. L. Jackson, T. H. Jensen, Y. Kamada, A. G. Kellman, L. L. Lao, R. J. La Haye, J. A. Leuer, J. B. Lister, T. H. Osborne, R. Snider, R. D. Stambaugh, E. J. Strait, A. D. Turnbull, Proc. 13th Int. Conf., Washington, D.C., 1990, in Plasma Physics and Controlled Nuclear Fusion Research, (IAEA, Vienna, 1991), Vol. I, p. 177.

${ }^{47}$ E. J. Strait, M. S. Chu, J. R. Ferron, L. L. Lao, E. A. Lazarus, T. H. Osborne, T. S. Taylor, A. D. Turnbull, Proc. 18th EPS. Conf., Berlin, 1991, in Controlled Fusion and Plasma Physics, Vol. 15C, Part II, (1991) p. 105.

${ }^{48}$ W. A. Howl, A. D. Turnbull, T. S. Taylor, L. L. Lao, F. J. Helton, J. R. Ferron, E. J. Strait, Phys. Fluids B 4, 1724 (1992).

${ }^{49}$ P. N. Yushmanov, T. Takizuka, K.S. Riedel, O.J.W.F. Kardaun, J.G. Cordey, S.M. Kaye, D.E. Post, Nucl. Fusion 30, 1999 (1990). 
${ }^{50}$ E. A. Lazarus, G. A. Navratil, C. M. Greenfield, E. J. Strait, M. E. Austin, K. H. Burrell, T. A. Casper, D. R. Baker, J. C. DeBoo, E. J. Doyle, R. Durst, J. R. Ferron, C. B. Forest, P. Gohil, R. J. Groebner, W. W. Heidbrink, R. Hong, A. W. Howald, C.-L. Hsieh, A. W. Hyatt, G. L. Jackson, J. Kim, L. L. Lao, C. J. Lasnier, A. W. Leonard, J. Lohr, R. J. La Haye, R. Maingi, R. L. Miller, M. Murakami, T. H. Osborne, L. J. Perkins, C. C. Petty, C. L. Rettig, T. L. Rhodes, B. W. Rice, S. Sabbagh, D. P. Schissel, J. T. Scoville, R. T. Snider, B. W. Stallard, R. D. Stambaugh, H. E. St.John, R. E. Stockdale, P. L. Taylor, T. S. Taylor, D. M. Thomas, A. D. Turnbull, M. R. Wade, R. D. Wood, and D. G. Whyte, "Higher Fusion Power Gain with Profile Control in DIII-D Tokamak Plasmas," submitted to Nucl. Fusion (1996).

${ }^{51}$ E. J. Strait, T. N. Casper, M. S. Chu, J. R. Ferron, C. B. Forest, C. M. Greenfield, A. W. Hyatt, L. L. Lao, R. J. La Haye, E. A. Lazarus, G. A. Navratil, B. W. Rice, A. C. C. Sips, F. X. Söldner, B. W. Stallard, T. S. Taylor, and A. D. Turnbull, "Improved Fusion Performance in Low- $q$, Low Triangularity Plasmas with Negative Central Magnetic Shear," Proc. 23rd EPS Conf., Kiev, 1996, to be published in Controlled Fusion and Plasma Physics.

${ }^{52}$ F. X. Söldner, V. Bhatnagar, T. N. Casper, C. Challis, A. Cherubini, M. S. Chu, G. Cottrell, L.-G. Eriksson, J. R. Ferron, B. Fischer, C. B. Forest, C. Gormezano, C. M. Greenfield, A. W. Hyatt, L. L. Lao, R. J. La Haye, E. A. Lazarus, T. Luce, G. A. Navratil, V. V. Parail, B. W. Rice, A. C. C. Sips, B. W. Stallard, E. J. Strait, T. S. Taylor, B. J. D. Tubbing, A. D. Turnbull, M. Wade, and D. Ward, Bull. Am. Phys. Soc. 41, 1520 (1996). 


\section{DISCLAIMER}

This report was prepared as an account of work sponsored by an agency of the United States Government. Neither the United States Government nor any agency thereof, nor any of their employees, makes any warranty, express or implied, or assumes any legal liability or responsibility for the accuracy, completeness, or usefulness of any information, apparatus, produce, or process disclosed, or represents that its use would not infringe privately owned rights. Reference herein to any specific commercial product, process, or service by trade name, trademark, manufacturer, or otherwise, does not necessarily constitute or imply its endorsement, recommendation, or favoring by the United States Government or any agency thereof. The views and opinions of authors expressed herein do not necessarily state or reflect those of the United States Government or any agency thereof. 